\title{
Europe's Hunters* and the Challenge of a Healthy Environment ${ }^{*}$
}

\section{Introduction}

Over the last ten to fifteen years, environmental protection has become a dominant concept both politically and sociologically. It has been realized that, unless we wish to destroy the very foundations of our existence, there are limits to how far we can exploit the Earth. The extinction of species of flora and fauna has become a major cause for alarm.

After the disastrous effects of two world wars, there were understandably other priorities-such as housing, food, and work-and so early warning voices went unheard. Hunters were among the minority who sounded the alarm, for example by the Conseil International de la Chasse et de la Conservation du Gibier (CIC), founded by French hunters in the 1920s, Hermann Lons as long ago as the end of the last century, and Professor Hans Krieg, one of the founders of the Deutscher Naturschutzring after World War II. However, even before the turn of the century, prominent hunting writers were referring to the deterioration in the environment for animal wildlife.

For these men and women, who today represent the overwhelming majority of hunters who are active in hunting organizations as represented by the Federation of Hunting Associations of the EEC, 'hunting'* involved first and foremost the preservation and restoration of nearnatural habitats, including the protection of the diversity of species, and also the sustained exploitation of all nonendangered species that, without hunting intervention, would continue to spread - for example Mallard (Anas platyrhynchos) or large herbivores such as Red Deer (Cervus elaphus) and roe deer (Caprellus spp.), and even Wild Boar (Sus scrofa). This sustained (hunting) exploitation, which as a rule simply means absorbing the natural increase in numbers, is comparable to ecologically-sound forestry management and, to some extent, also to farming.

\section{Farming Practices Change.}

Farmers have developed and cultivated the land of Europe over many centuries, up until now largely without harming Nature, but also often without satisfying the population's needs - bad harvests, whatever the cause, were apt to be followed by famine and misery. Not until the beginning of industrialization, with the invention and production of mineral fertilizers and pesticides and mechanization, did yields rise to their present level in a way that previously would have been inconceivable.

The EEC's agricultural policy went one step further; the result was large-scale single-crop farming that was amenable to mechanization. Hedges, thickets, and grass verges, all widely disappeared, near-natural field tracks were covered with concrete or asphalt, increasing erosion caused by unbroken wind was treated with even more fertilizers, weeds were suppressed with herbicides, and invertebrates with pesticides. As a result, the native Grey Partridge ( $P(r$ dix perdix) and Hare (Lepus europaeus), for example. and even the hardy introduced Ring-necked Pheasant (Phasianus colchicus), suffered a sizeable reduction in their natural habitats and, consequently, populations.

So as to avoid any misunderstanding, it should be emphasized that individual farmers are in no way re-

\footnotetext{
* In this context meaning mainly shooters of game-birds and mammals, rather than hunters or coursers using hounds to catch their prey.-Ed.

$\dagger$ Communicated to Centre Naturopa, Council of Europe, B.P. 431 R6, F-67006 Strasbourg Cedex. France. to whom our gratitude is due and warmly expressed. - Ed.
}

sponsible for this development. They were forced by politics, and in order to protect their livelihood - which otherwise could not keep up with the general pace of salary increases - to farm, and indeed over-farm, every lasi square metre of agricultural acreage.

\section{Forestry Collaboration Needed}

For a long time, forestry management was also more interested in economic than ecological priorities, and in many places this is still the case today. So. what is the challenge facing hunters? Let us begin with forests, which in many parts of Europe have been damaged by pollution and which, it is now generally agreed. need to be more ecologically managed than hitherto: species of trees should be chosen to fit the given habitat, forests should be mixed and complex, and softwood deciduous trees such as alders (Alnus spp.). Aspen (Populus tremula), and willows (Salix spp.), should now be left standing having for a long time been purposefully cut back. This must not be jeopardized by excessive numbers of hoofed game such as Red Deer, Roe Deer, or Chamois (Rupicapra capra). In other words, there is a need for effective hunting, without disturbing a desirable species' characteristic rhythm of life and social behaviour through too much hunting, often in such a way that more harm is done by even less game.

However, society must also realize that animal wildlife needs an undisturbed habitat. 'Soft' tourism and restrictions on when and where sports such as skiing, hang-gliding, mountain bike-riding, flying, motor and water sports. may be practised, are essential; but, within limits, access should be confined to paths, and there should be secluded Nature zones with no access to the public.

The often insufficient feeding-ground for wild animals in 'artificial' forests must be sensibly improved by hunters and forest owners working together; wild grazing-land in forests, as far as possible in or near the areas where deer are found during the day, and which provide suitable food for each species during the entire vegetation period, should be cleared to total from 1 to $2 \%$ of the forest floor. A reduction in the damage caused by game more than compensates for the loss of woodland!

However, an ecological wood is also a prerequisite for the preservation of countless other species, such as Capercailzie (Tetrae urogallus), as well of course as owls, woodpeckers, and even forest ants.

\section{Protect the Man-made Landscape}

There has been a change of thinking which is reflected in the EEC's agricultural policy, and also in the minds of many farmers. Surpluses that can no longer be paid for, and damage to soil and vital ground-water, both call for reflection. Our priority for the future should not be increasingly high yields, but the protection of the Man-made landscape. and for this society naturally has to pay an appropriate price. However, the hunting fraternity, in close cooperation with agriculture, presents a great opportunity for creating new habitats for animal wildlife, including game such as roe deer and hares, partridges and the Ring-necked Pheasant. The EEC's 'farmland set-aside' scheme, and the preretirement scheme for farmers in the Federal Republic of Germany, should be used accordingly, even if the majority of member States are unfortunately dilatory in putting these schemes into effect.

As hunters, we and our organizations should do all that we can to work together with the farming community to 
create a comprehensive network of biotopes, and we should not hesitate to invest time and money in this task.

Of course the States or society must provide basic compensation for the farmers' loss of agricultural production in these circumstances, but we ourselves should bear the responsibility for organizing the land for preservation, in which case it would certainly make sense to involve the farmer concerned in some return of appropriate additional remuneration or supply of seed or plants for hedges, bushes, and thickets.

The aim should not be to allow set-aside fields to become untended fallow land; neither from an ecological point of view nor with respect to the surrounding fields should that continue. The biotope areas (according to situation and the prevailing animal species) need to be arranged wisely, to suit the landscape. In other words they should be as "natural' as possible, and this applies to all biotopes, ranging from wetlands for amphibians and dragonflies, to the nowrare dry grasslands and meadows. Hedges and thickets must also be maintained or reconstituted, eg. with such species as:

Spindle (Euonymus europaeus)

Privet (Ligustrum vulgare)

Dogwood (Cornus sanguinea)

Various species and types of willow (Salix)

Lime (Tilia cordata)

Elder (Sambucus nigra)

Robinia (Robinia pseudoacacia, introduced but widely naturalized)

Rowan (Sorbus aucuparia) and Wild Service-tree (S. torminalis)

Whitebeam (S. aria)

Service-apple ( $S$. domestica)
Hawthorn (Crataegus monogyna)

Sloe (Prunus spinosa).

\section{Set Aside Strips}

Even where there are no set-asides, it should be possible for strips, 3 to 5 metres wide, to be taken out of production along paths, streams, and ditches, etc., leasing them out if necessary, to protect them as 'wild land'. Countless animal species would thus be provided with a habitat of shelter and food. Of course, none of these areas should be fertilized or sprayed; nor should any attempted amelioration be carried out on them. Areas with numerous dehiscent fruits should be mown once a year after the seeds have fallen, whereas wild grazing meadows should be mown in sections, so that there is always some fresh grazing. It should be observed that these measures would benefit all animalwildlife and certainly not only game animals.

Decisive action on the part of Europe's hunters would. however, confirm the sometimes disputed assertion that 'hunting is applied conservation too', and would legitimize our claim to carry out sustained exploitation of wild species. However, as hunters, we should not disguise the fact that, although we hunt to enjoy Nature, we do also like to 'bag' our quarry. On the other hand, we are prepared to use our own efforts and money, without the help of subsidies. to restore the environment to the healthier state that it formerly enjoyed.

Alfred Hubertus Neuhaus, President Landesjadverband Baden-Württemberg Postfach 1660

D-6830 Schwetzingen

Federal Republic of Germany.

\section{The Commonwealth of Learning}

This is a new International Organization established by Commonwealth Heads of Government in September, 1988. Its aim is to widen access to education by promoting cooperation in 'distance education' among Commonwealth countries. Enhanced educational opportunity through distant study is considered to be crucial in meeting human resource development needs in member states.*

The Commonwealth of Learning will work with colleges and universities throughout the Commonwealth, complementing and supporting their work in developing the most cost-effective means for delivering learning at a distance.

\section{What Can it Do?}

The Commonwealth of Learning will work towards three goals: good 'distance education' depends on good materials. Considerable expertise has been developed in many Commonwealth educational institutions on the development and distribution of distance-learning materials. The sharing of such expertise and resources can improve, extend, and enrich, programmes throughout the Commonwealth. The first goal of The Commonwealth of Learning, therefore, will be to promote the sharing of distance teaching materials and to support the development of new materials to meet particular educational needs.

\footnotetext{
* and we would affirm, due environmental awareness, which it is much-to-be-hoped The Commonwealth of Learning will stress, especially in the Commonwealth itself which includes something like one-quarter of the world's living human population. -Ed.
}

The further development of high-quality 'distance education' programmes will require up-to-date information on how materials may be acquired or produced, and on having access to appropriate communications systems. The second goal of The Commonwealth of Learning is to strengthen institutional capacities by providing staff training, fostering communications, establishing an information base on distance education programmes and services, and supporting collaboration in evaluation and research.

People who study at a distance do not have access to conventional student services and study-support systems. It is widely acknowledged in the field of distance education that the learning of students is improved when alternative methods of providing these support-systems are available, and when students have greater access to these services than is generally the case. The third goal of The Commonwealth of Learning is to assist distance teaching institutions in providing better services than formerly to students, improving study support-systems, and facilitating the transfer of credit between Commonwealth institutions.

The Commonwealth of Learning is committed to achieving these goals in distance education through consultation, cooperation, and collaboration. It will not enrol individual students. Its function is to work with bona fide colleges and universities. It will not concentrate all of its attention on highly sophisticated technology: The Commonwealth of Learning is as much interested in simple forms of technology, including print, as it is in more advanced communication technology involving satellites and computers. 